Review

\title{
History and Development of Autologous Stem Cell Transplantation for Acute Myeloid Leukemia
}

\author{
Norbert Claude Gorin*,(D) \\ Department of Hematology and Cell Therapy, and EBMT Global Committee, Hopital Saint-Antoine APHP, Paris Sorbonne University, Paris, France
}

\author{
ARTICLE INFO \\ Article History \\ Received 19 April 2021 \\ Accepted 03 June 2021 \\ Keywords \\ Autologous stem cell \\ transplantation \\ acute myelogenous leukemia \\ cryopreservation \\ review \\ history
}

\begin{abstract}
This review describes the development of cryopreservation, the birth of autologous stem cell transplantation (ASCT) and its past and present use to consolidate adult patients with acute myelogenous leukemia (AML). It summarizes the first autografts in patients in relapse, the experience of autografting in complete remission (CR), using bone marrow unpurged or purged in vitro with cyclophosphamide-derivatives, and the important shift to peripheral blood stem cells. The review also discusses the results of recent studies in favor of the use of ASCT to consolidate good- and intermediate-risk patients who reach CR with no detectable minimal residual disease, and those which support the inclusion of maintenance therapy post autograft with hypomethylating agents, anti-BCL-2, and, possibly, in the future, anti AML chimeric antigen receptor-T cells. Carefully applied to well-selected patients, ASCT may regain interest, because of its simplicity, its reduced toxicity, lower non-relapse mortality and better quality of life.
\end{abstract}

(C) 2021 International Academy for Clinical Hematology. Publishing services by Atlantis Press International B.V. This is an open access article distributed under the CC BY-NC 4.0 license (http://creativecommons.org/licenses/by-nc/4.0/).

\section{INTRODUCTION}

The real story of autologous stem cell transplantation (ASCT), in general, and ASCT for acute leukemia in particular, starts with the story of stem cell cryopreservation [1].

Although studies on the effect of cold on viability of cells go back a very long time with Reaumur (1736) and Spallanzani (1787) as pioneers, the real modern and fruitful impetus resulted from the devastating observations of the two atomic bomb drops on Hiroshima and Nagasaki (Japan) at the end of World War II. These generated in the scientific and medical community a frenzy to determine how to cryopreserve stem cells, and to perform allogeneic SCT (allo-SCT), both as preventive measures from lethal irradiation. This was the time when commercial advertising, especially in United States, promoted "nuclear bomb shelters in your garden", and the time when the pioneers of allo-SCT with an identical sibling, were presenting their first results at international transplant meetings, namely Jean Dausset (Paris, France, Nobel Prize 1980), Donald Thomas (Seattle, USA, Nobel Prize 1990), Georges Santos (Baltimore, USA), Dirk van Bekkum (Leiden, the Netherlands), Georges Mathe (Villejuif, France), Jon van Rood (Leiden, the Netherlands).

Research on stem cell cryopreservation lasted about 10 years, before giving birth in 1976 to ASCT, which was, at that time, autologous bone marrow transplantation (ABMT). ASCT was evaluated as a means to administer the highest possible doses of chemotherapy/

"Email: gorinclaude@gmail.com

Peer review under responsibility of the International Academy for Clinical Hematology irradiation to obtain maximum tumor reduction with the maximum tolerated dose defined by all organ toxicities.

For approximately another 10 years, effort was put into increasing high-dose therapy modalities for the treatment of hematological malignancies and solid tumors. Various high-dose combination therapies were generated. Some copied the so-called conditioning regimen, built to prepare for an allogeneic transplant, such as cyclophosphamide + total body irradiation (TBI) or busulfan + cyclophosphamide (BUCY). Other protocols were more specifically adapted to a specific disease such as the BCNU, etoposide, cytosine-arabinoside, melphalan (BEAM) or the cyclophosphamide, BCNU, etoposide (CBV) for lymphomas.

For acute myelogenous leukemia (AML), ASCT has been a special challenge. When we performed the first ASCT in Hopital SaintAntoine in Paris, in 1976, less than $10 \%$ of patients with AML could be allo-transplanted, since the age limit was 35 years old and the probability of having a genetically identical sibling was less than 25\%. Applying high dose consolidation with ASCT covered therefore an unmet need, because it was available to every patient including those aged up to 70 years, with slightly reduced-dose regimens, such as the BCNU, ARA-C, amsacrine, etoposide (BAVC) pioneered in Roma. Severe criticism came from everywhere, in view of the risk of reinfusing leukemic stem cells with the autograft (even though this was collected in CR). For about 15 years, the interest was focused on in vitro purging of the collected marrow from residual leukemic cells.

About 50,000 ASCT for acute leukemias (AML and acute lymphocytic leukemia) have been performed so far, most of them before 
the year 2000. ASCT for AML has benefitted from a very low nonrelapse mortality (NRM) but suffered from a high relapse incidence (RI). In contrast, allogeneic transplantation's graft-versus-leukemia (GVL) immunological effect has endowed it with a much lower RI, but an increased NRM.

In the last two decades, many major improvements have facilitated allo-transplants, most notably the possibility of finding a donor for almost every transplant eligible patient and the use of reduced intensity conditioning. Today, ASCT is widely used for the treatment of lymphoid malignancies. The number of ASCT performed in Europe each year in AML patients, as recorded by the European Society for Blood and Marrow Transplantation (EBMT), is fewer than 300 .

Yet the story of ASCT may not be over. The management of AML has been greatly improved in the past decade. We now have a better definition of AML risk groups by combining cytogenetics with molecular markers. We can better evaluate minimal residual disease (MRD) and identify good quality remissions with undetectable MRD (negative) by flow cytometry and/or molecular biology. In several AML subtypes (FLT3-ITD or mutated, IDH1 and 2), we now have targeted therapies. We also have new agents such as hypomethylating agents (decitabine/5-azacytidine), BCL-2 inhibitors e.g. venetoclax, and new monoclonal antibodies such as anti-CD47 (magrolimab). Most of all, the introduction of maintenance therapy post-transplant, which was inconceivable even a few years ago, is now being evaluated by randomized studies.

Taking these improvements into account, recent retrospective studies of ASCT in AML indicate that there is indeed a population of patients that would benefit from ASCT rather than allogeneic transplantation.

\section{CRYOPRESERVATION OF STEM CELLS}

The danger of TBI leading to fatal bone marrow (BM) aplasia, as observed following the atom bomb explosions in Hiroshima and Nagasaki in 1945 led to speeding up of research in stem cell cryopreservation, and numerous animal models were developed immediately after World War II. It is noteworthy that the demonstration in 1955, by Barnes and Loutit [2], that BM could be successfully cryopreserved (after the initial successful work on preservation of bull sperm by Polge et al. [3] in 1949) did not allude to the preservation of marrow stem cells but rather, to the preservation of a so called "radiation recovery factor".

Several preclinical models in mice [4], rabbits [5], monkeys [6,7] and dogs [8-13] demonstrated the ability of frozen marrow to engraft and reconstitute hematopoiesis. In 1975, we developed a canine in vivo model $[8,10]$ to assess the viability of stem cells frozen and stored for prolonged periods in liquid nitrogen. We used a freezing scheme (Figure 1) in which BM suspended in tissue culture medium (M199) with a final 10\% dimethyl sulfoxide (DMSO) concentration was refrigerated at a fixed cooling rate of $-1^{\circ} \mathrm{C} / \mathrm{min}$ [8] with permananent temperature recording to detect the release of the heat of fusion and supercool at this very moment by massive introduction of liquid nitrogen. The rationale was to avoid the destruction of cells due to the reorganization of extra-cellular ice induced by this release, similar in a way, to a ship imprisoned in a melting and re-icing floe. Forty-six foxhounds received TBI (10 Gy) followed by the infusion of autologous fresh BM or frozen

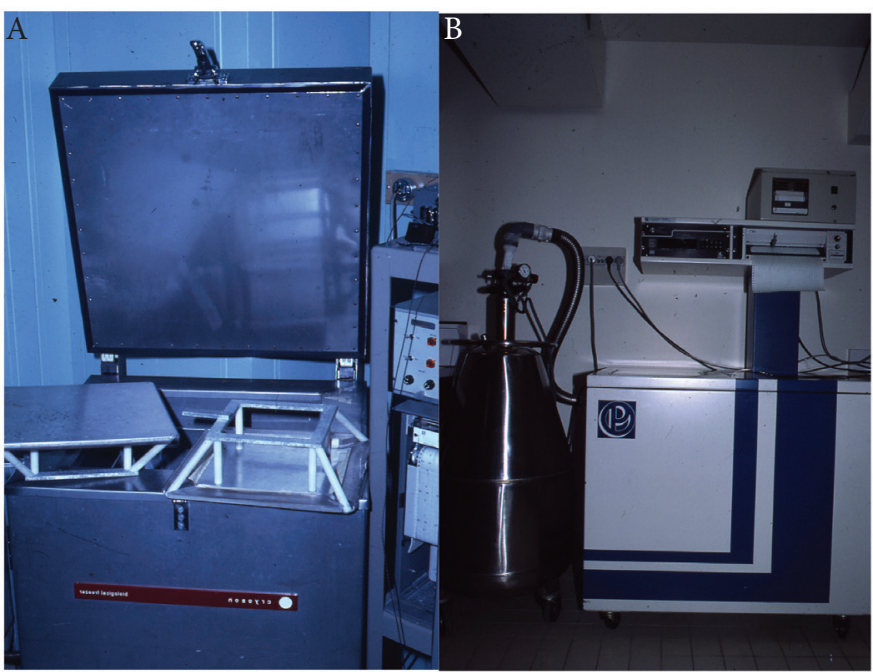

C

DIAGRAM OF A REPRESENTATIVE FREEZING CURVE

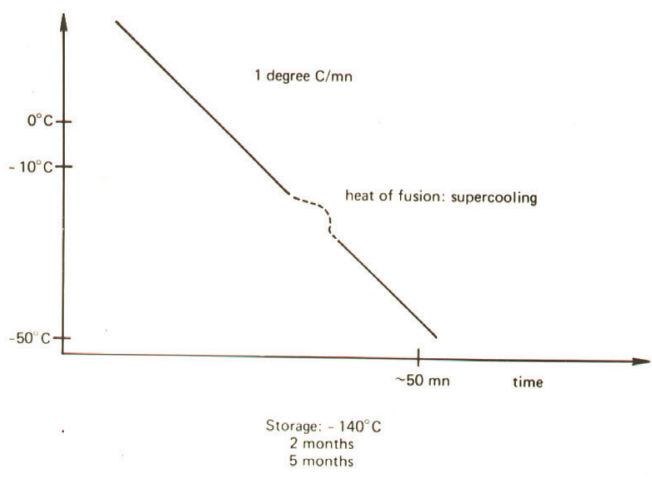

Figure 1 The first programmed freezing apparatus. (A) «Cryoson» (Midden Beemster, The Netherlands) used at Hôpital Saint-Antoine, Paris, from 1974 to 1995. (B) Nicool, the freezing apparatus from "Air liquid" used afterward. (C) The ideal freezing curve with a $-1^{\circ} \mathrm{C} / \mathrm{min}$ constant cooling rate and supercooling at the release of the heat of fusion to avoid thermic shock.

BM stored for $2-5$ months in the vapor phase of liquid nitrogen $\left(-140^{\circ} \mathrm{C}\right)$. The results demonstrated a direct relationship between the dose of BM infused and the percentage of successful engraftments. The minimum dose of fresh $\mathrm{BM}$ for autologous engraftment was between 0.1 and $0.25 \times 10^{8}$ nucleated cells $/ \mathrm{kg}$. There was no difference between fresh BM and BM stored for 2 months (100\% recovery of frozen stem cells) (Figure 2A). Parallel in vitro studies showed destruction of mature myeloid elements but perfect ultrastructure of frozen and thawed lymphocytes, plasma cells and erythroblasts (Figure 2B). Also, frozen, and thawed marrow grown in short-term culture produced normal metaphases, with no chromosome aberrations. DNA synthesis evaluated in $10^{6}$ nucleated cells before and after preservation was similar. In 1975, the medical scene for ABMT was set.

We later showed, in humans, that over $75 \%$ of the proliferative capacity of the cryopreserved granulocyte-macrophage colony-forming unit (CFU-GM) progenitors was recovered on thawing, but that DMSO caused substantial loss of progenitor cells within $20 \mathrm{~min}$ at $4^{\circ} \mathrm{C}[14]$ and that the recovery of CFU-GM from cryopreserved marrow was predictive of engraftment [15]. We therefore decided 


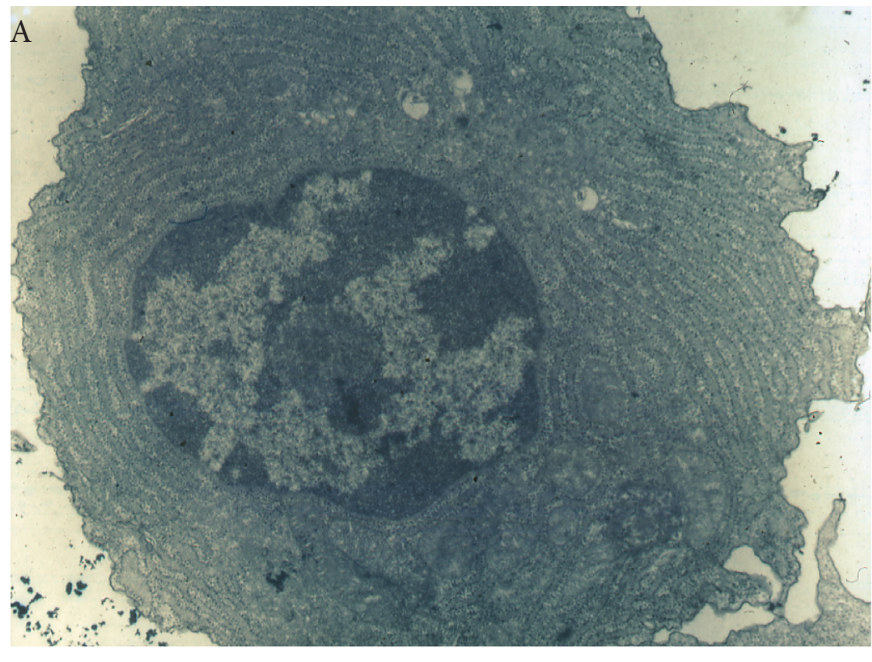

B

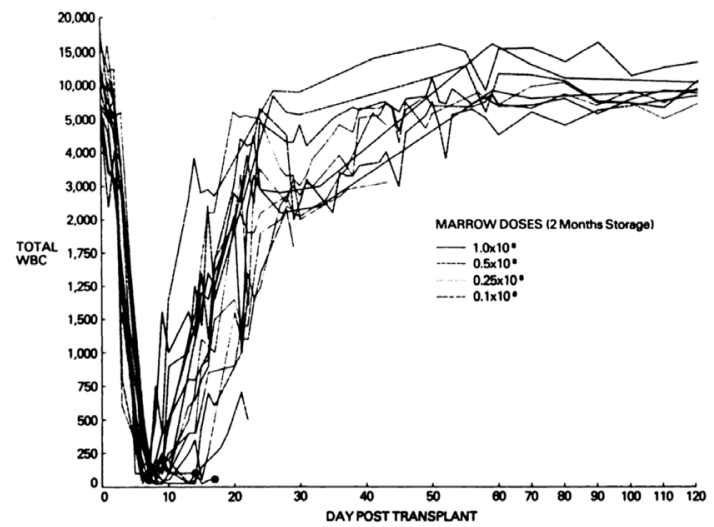

Figure 2 The preclinical canine model. (A) A well cryopreserved plasmocyte with no ergastoplasm disruption. (B) Composite of total leukocyte counts for dogs submitted to total body irradiation followed by infusion of various doses of frozen autologous marrow stored for 2 months.

to freeze in parallel to the stem cell graft itself, a small control probe sample, which could be tested before the autograft infusion. This was especially useful after a long storage duration or uncertainty about a possible breaking of the cold chain [16].

Theoretically, stem cells stored at $-140^{\circ} \mathrm{C}$ in the gas phase of liquid nitrogen or even deeper at $-196^{\circ} \mathrm{C}$ can be preserved indefinitely, since all enzymatic processes are totally blocked, which is not the case at lower temperatures of $-20^{\circ} \mathrm{C}$ or even $-70^{\circ} \mathrm{C}$. Safe preservation for periods as long as 11 years have been reported [17].

Many teams have tried to simplify the cryopreservation technique or to replace it by storage of the harvested marrow in a conventional refrigerator at $4^{\circ} \mathrm{C}$. However, it was shown very early on that marrow could not be preserved for more than $56 \mathrm{~h}$ [18]. In contrast, and more recently, it was observed that peripheral blood stem cell (PBSC) collected and somewhat purified by leukapharesis (LK), can survive storage at $4^{\circ} \mathrm{C}$ for up to 6 days but not longer, enabling carefully planned autografts to be performed in patients receiving short pre-transplant regimens [19-24]. Stem cell cryopreservation opened the door for autologous transplantation and a decade later to cord blood storage.
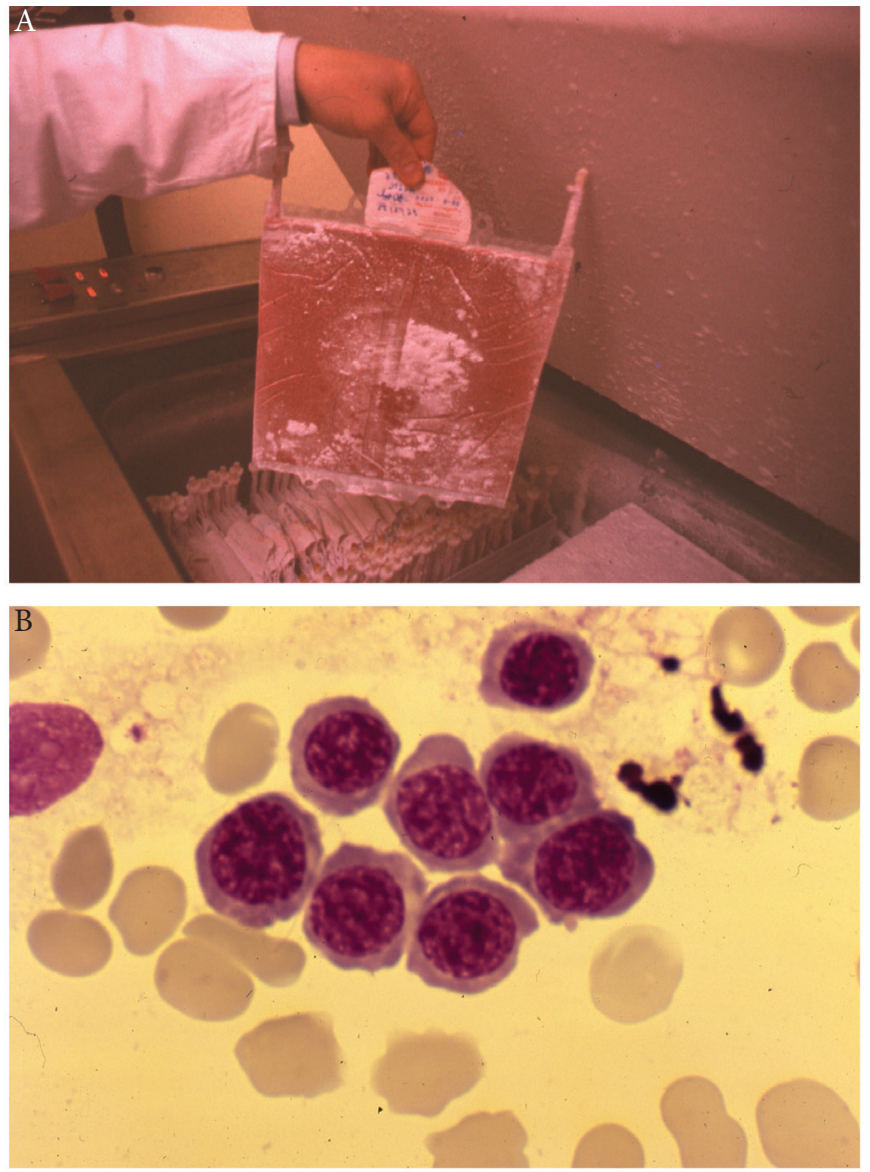

Figure 3 The first autologous stem cell transplantation in man (1976). (A) A polyolefin bag containing marrow of one of the first autografted patients, squeezed between the two plates presented on Figure 1 and frozen following a program of $-1^{\circ} \mathrm{C} / \mathrm{min}$ with abrogation of the heat of fusion. Polyolefin bags were fragile and could break on thawing. They were later replaced by Teflon-Kapton bags. (B) Marrow aspirate 14 days after the first patient was autografted at Hopital Saint-Antoine, Paris. The patient received his marrow collected in first remission of acute myelogenous leukemia and cryopreserved in the gas phase of liquid nitrogen $\left(-140^{\circ} \mathrm{C}\right)$ in 1976 : the first erythroblastic nest attesting for engraftment.

\section{HISTORICAL AUTOLOGOUS STEM CELL TRANSPLANTATION FOR ACUTE MYELOID LEUKEMIA}

\subsection{The Premise}

Following our pioneering work on stem cell cryopreservation [8-10,25] with the demonstration of its efficacy in a preclinical dog model, we performed at hopital Saint-Antoine, in Paris in February 1977, the first ABMT in a 28-year old male patient with AML $[26,27]$ (Figure 3 ). The patient had gone into an early drug resistant relapse with multiple chloromas (one of them on an upper eyelid leading to a complete obstruction of the field of vision), while on maintenance chemotherapy with methotrexate and 6-mercaptopurine, 7 months after the induction of a first CR (CR1). He received 
a myeloablative regimen followed by marrow collected while in early remission and cryopreserved in the gas phase of liquid nitrogen. The patient experienced a second CR (CR2) of short duration. A second patient experienced a CR2 which lasted 4 years before relapsing. From these initial observations until 1982, we and several other teams followed this approach and demonstrated that in adult patients with AML in relapse, a high rate of CR could be achieved, which for the majority, lasted longer than the initial CR. The term "inversion" was used at that time to draw attention to such an unusual evolution contrasting with the so called "natural" evolution of the disease. ABMT was tested in parallel in patients with refractory and relapsing lymphomas and myelomas and it was observed that the kinetics of hematopoietic (neutrophils and platelets) recovery in AML were much longer than in lymphoid malignancies [26-29].

\subsection{Autologous Bone Marrow Transplantation with Purged and Unpurged Marrow}

From 1982, the use of high dose myeloablative therapy as consolidation with ABMT was applied to patients in CR. However, concerns were raised about the risk of reinfusing leukemic stem cells with the autograft usually harvested in early CR1. A minimum number of consolidation chemotherapy courses preceding marrow harvesting was found to be beneficial to minimize this risk and referred to as "in vivo purging". Also, and even more importantly, techniques of in vitro purging of the autograft were developed prior to cryopreservation and reinfusion. The Baltimore team showed that 4-hydroperoxy cyclophosphamide (4HC), a direct acting cyclophosphamide catabolite, could selectively destroy in vitro leukemic stem cells, while sparing normal stem cells protected by a high level of aldehyde dehydrogenase. In a highly demonstrative experiment, Sharkis et al. [30] prepared cell suspensions of normal rat marrow mixed with rat acute myelogenous leukemia cells which they incubated in vitro with graded doses of $4 \mathrm{HC}$. The cell suspensions were injected into syngeneic rats prepared with a lethal dose of TBI. Animals injected with these cells survived fatal irradiation induced aplasia. Animals given cell suspensions incubated with the lower doses of $4 \mathrm{HC}$ showed prolonged survival before death from leukemia while animals given cell suspensions incubated with higher doses of $4 \mathrm{HC}$ survived lethal irradiation and were cured of leukemia. These studies clearly established that tumor cells may be eliminated from normal marrow suspensions without completely destroying the pluripotent stem cells. Several teams throughout the world, in the United States [31], France [32], including our team in Paris [33-36], Germany [37] and Italy started programs of ABMT with high dose cyclophosphamide and TBI (single dose at $10 \mathrm{~Gy}$ or fractionated at $12 \mathrm{~Gy}$ ) using marrow purged in vitro with either $4 \mathrm{HC}$ in the United States, or mafosfamide (a related compound) in Europe. Most teams treated the marrow with fixed doses of mafosfamide while we adjusted the dose to what we considered to be the maximum tolerated dose defined as sparing 5\% residual CFU-GM $[33,35,36]$. Interesting observations resulted from this approach.

On technical grounds, it was confirmed that in AML, but not in lymphoid malignancies, marrow and purging with mafosfamide resulted in delayed kinetics of recovery of hematopoiesis; we observed engraftment of neutrophils by day 30 only (range, 12-153), and platelets by day 90 only (range, 19-850) [34]. Various chromosome abnormalities including in chromosome 1 were detected years after the autograft, with no relation to the initial leukemia and no detectable impact on outcome. Whether they resulted from mafosfamide treatment or previous TBI given with the pre-transplant regimen, could not be determined $[38,39]$. Interestingly, it was observed that clonogenic leukemic progenitor cells in AML are highly sensitive to cryopreservation itself (six different methods were tested) which therefore contributed to purging in addition to mafosfamide [40].

Several clinical studies supported this approach. Our team at Hopital Saint-Antoine [41] reported on a total of 229 consecutive patients autografted in CR with marrow purged with mafosfamide. The patients receiving the highest stem cell doses evaluated before purging and the most aggressively treated with mafosfamide, as evaluated by the fraction of residual CFU-GM, had a treatment-related mortality of only $5 \pm 2 \%$, a leukemia-free survival (LFS) of $70 \%$, and an overall survival (OS) of $77 \pm 7 \%$ at 10 years post transplantation.

The EBMT published two retrospective studies in 1990 and 1992 $[42,43]$ comparing the outcome of AML patients autografted while in CR with marrow, purged or unpurged. The second report involved 59 European teams that had reported 919 autografts for consolidation of AML up to December 31, 1989. Marrow was purged with mafosfamide in 269 patients. Multivariate analysis showed significant efficacy of marrow purging in AML in CR1. In patients autografted after TBI, the RI with purged marrow was $29 \%$ versus $50 \%$ with unpurged marrow, and $16 \%$ versus $60 \%$ when considering only those autografted within 6 months of CR. In slow responders, the results were $20 \%$ versus $61 \%$, significantly in favor of purging, whereas the RI were similar in rapid responders. The relapse patterns were different in that the plateau for persisting remission started at 23 months with purged marrow and at 32 months with unpurged marrow. It was concluded that purging was most likely to bring benefit to a specific category of patients, i.e. those transplanted early, and slow responders, in whom the probability that leukemic cells might still persist in the graft at the time of collection was higher. These data were confirmed 9 years later by an International Bone Marrow Transplant Registry (IBMTR) retrospective study on patients with AML autografted in the United States [44]. In this latter study of 294 patients, multivariate analysis showed that patients receiving 4HC-purged transplants had a lower relative risk (RR) of treatment failure than those receiving unpurged transplants $(\mathrm{RR}, 0.69, p=0.12)$ in the first posttransplant year and thereafter (RR, 0.28, $p<0.0001)$. Adjusted 3 -year probabilities of LFS, were 56\% and 31\% after $4 \mathrm{HC}$-purged and unpurged transplants in CR1, respectively. Corresponding probabilities in CR2 were 39\% (25-53\%) and 10\% (1-29\%). The authors concluded that grafts purged with $4 \mathrm{HC}$ were associated with higher LFS after ABMT for AML.

In 1992 Malcolm Brenner [45,46], using gene marking studies, demonstrated that leukemic cells harvested with an autologous graft could contribute to relapse. The neomycin resistance gene in a retroviral vector was used to mark autologous unpurged marrow infused into patients; in the few patients who relapsed, the resurgent blast cells contained the neomycin-resistance gene marker, clearly indicating that they originated from the graft. Similar observations were made with neuroblastomas, chronic myelocytic leukemia, and 
solid tumors. It was felt at that time that the proof of principle was strongly established to support routine in vitro purging. However even though the technique of marrow purging was relatively simple, it was not available in most centers. From 1994, peripheral blood (PB) became the major source of stem cells and using $4 \mathrm{HC}$ or mafosfamide to treat large volumes was more complex. Centers pursuing their programs of high-dose consolidation with autografting in AML in CR shifted to PBSC with no in vitro purging.

\subsection{The Shift to Autologous Peripheral Blood Stem Cell Transplantation}

The use of PBSC to autograft patients with AML was an important turning point. It benefitted from all the technical advantages of PB over marrow collection (simplicity, lower risk, no anesthesia or operating room, and easier planification of LK). Unfortunately for AML patients, the rapid shift to $\mathrm{PB}$ probably resulted in an increase in RI. Early experiences with PBSC transplants were disappointing and, in fact, suggested that at least if mobilization and collection followed immediately after induction, a large proportion of leukemic clones were mobilized. Massive reinfusion of these cells into patients led to early relapses $[47,48]$. Leukapheresis after several consolidation courses for "in vivo purging" was then recommended and it was shown in a French randomized, multicenter study that patients undergoing LK after a minimum of two chemotherapy courses had a trend toward a lower RI ( $47 \%$ versus $57 \%, p=0.1)$ and a better LFS ( $48 \%$ versus 39\%, $p=0.1$ ) than patients undergoing LK after only one chemotherapy course [49].

A first EBMT retrospective study between BM (purged and unpurged) and $\mathrm{PB}$ as sources of stem cells for autografting suggested better results with BM [50]: in this comparison, 1393 patients undergoing either a PBSC $(n=100)$ or purged $(n=252)$ or unpurged $(n=1041)$ BMT were compared. Hematopoietic recovery was significantly quicker after PBSC than after either purged or unpurged BMT. The 2-year LFS, RI and OS for the entire study population was $52 \%, 43 \%$ and $58 \%$. After PBSC transplants, LFS and RI were $44 \pm 6 \%$ and $50 \pm 6 \%$ and did not differ significantly from that found for unpurged BM transplants (49 $\pm 2 \%$ and $45 \pm 2 \%$; $p=\mathrm{NS})$. However, LFS $(57 \pm 3 \%)$ and RI $(37 \pm 3 \%)$ of patients undergoing purged BMTs were significantly better than that found for PBSC patients ( $p=0.01$ and 0.006 , respectively). As some characteristics of patients undergoing $\mathrm{PB}$ or purged BMT differed, the better outcome observed for purged $\mathrm{BM}$ over $\mathrm{PB}$ patients could not be firmly established.

In a subsequent EBMT retrospective study [51], the Acute Leukemia Working Party analyzed 2165 patients who received autografts (1607 PBSC and 558 BM) from 1994 to 2006. Relative to the time of CR1, PBSC transplants were performed earlier than BM transplants. Because a poorer outcome was associated with a shorter interval from CR1 to transplantation, patients were divided into three transplant groups: BM, early PBSC ( $\leq 80$ days after CR1), and late PBSC ( $>80$ days after CR1). In a multivariate analysis adjusted for differences between groups and centers, RI was higher with both early PBSC $(56 \pm 3 \% ; p=0.006)$ and late PBSC transplantation ( $46 \pm 2 \% ; p=0.01)$ as compared with BMT $(39 \pm 2 \%)$. This translated into a significantly worse LFS for early PBSC transplantation $(36 \pm 3 \% ; p=0.02)$ and a trend towards a poorer LFS for late PBSC $(46 \pm 2 \% ; p=0.06)$ as compared with BMT $(52 \pm 2 \%)$. It was concluded that for patients with AML in CR1, the risk of relapse was greater with PBSC transplantation than with BMT.

Indirect evidence that mobilization of stem cells also mobilized residual leukemic progenitors resulted from the observation first by the European Organization for Research and Treatment of Cancer (EORTC) [52] as early as 2003 and later confirmed by the EBMT that patients autografted with the highest dose of CD34(+) cells obtained with LK had a higher RI and a lower LFS: the EORTC concluded that a high percentage of CD34(+) cells in autologous AML PBSC products reflected inadequate in vivo purging in a subgroup of patients with poor clinical outcome. In an EBMT study [51] of 772 patients autografted more than 80 days after CR1, the highest quintile for CD34(+) stem cell dose infused $\left(>7.16 \times 10^{6} / \mathrm{kg}\right)$ was selected as the cutoff point. Relapse was more frequent in patients who received the highest dose $(\mathrm{HR}=1.48 ; p=0.005)$, and LFS was worse $(\mathrm{HR}=0.72 ; p=0.01)$.

A more recent study of 956 patients (which led to the use of a nomogram for Individualized Prediction of LFS after ASCT) also found that BM was associated with better outcomes than PBSC [53] but stem cell source was removed from the score calculation because of the possibility of associated confounding factors.

A randomized study comparing autologous BMT versus autologous PBSC has never been done and unfortunately is unlikely, due to the collection of mobilized PBSC being much easier and more importantly, the kinetics of engraftment being much shorter than with BM, resulting in a reduction of the duration of aplasia and NRM.

Currently, for these practical reasons, the established routine is to use PBSC for autografting AML patients. However, in view of previous experience, a minimum of two high-dose chemotherapy consolidation courses is recommended before LK as well as careful monitoring of MRD by either flow cytometry and/or molecular biology so that mobilization is carried out on patients with no detectable MRD. The verification of the absence of detectable residual disease in the collected PBSCs (the autograft itself), is an additional safety measure.

\subsection{Retrospective Studies with Bone Marrow}

From 1976 to 1995, reports of ASCT in AML concerned single institutions or data from registries. The situation was similar for allo-transplants.

Results from these reports are summarized in a previous review [54]: For patients autografted with unpurged marrow, the LFS ranged from $34 \%$ (Sutton, UK) to $70 \%$ (Bologna, Italy) at 5 years with a median of $50 \%$. With purged marrow, LFS ranged from $41 \%$ (Baltimore, USA) to $80 \%$ (Manchester, UK); our own series with cyclophosphamide + TBI and purging with adjusted doses of mafosfamide on 64 patients had a LFS of $58 \%$ and a RI of $25 \%$. A similar series of 50 consecutive patients autografted in San Francisco with marrow purged by $4 \mathrm{HC}$ was reported with an LFS that plateaued at $70 \%$ and a RI of $27 \%$ with a median follow up of 7 years $[55,56]$. In CR2, the two largest series came from Baltimore (purging with $4 \mathrm{HC}$ ) with a LFS of $30 \%$ in 80 patients, and from 
Rome (no in vitro purge) in 60 patients who received the specific BAVC pre-transplant regimen with a LFS of $42 \%$ at 10 years [57].

The general assumption during this period was that ABMT with no in vitro purging, as consolidation for all consecutive adult AML patients, with no stratification for cytogenetics, resulted in a $50 \%$ LFS in CR1 and about $30 \%$ in CR2. ABMT with in vitro purging was credited with better outcome but no comparison was possible.

As can be easily seen from these results the major drawback was a high RI.

Interest in single institution reports disappeared when results from randomized studies became available.

\subsection{Randomized Studies in CR1 with Bone Marrow or PBSC}

In 1995, Zittoun et al. [58] published the first phase 3 randomized study comparing the value of high dose consolidation followed by ABMT. Patients with AML in CR1 and with an HLA-identical sibling were assigned to undergo allogeneic BMT; the others were randomly assigned to undergo ABMT (with unpurged bone marrow) or a second course of intensive chemotherapy, combining high-dose cytarabine and daunorubicin. The projected rate of disease-free survival (DFS) at 4 years was $55 \%$ for allogeneic transplantation, $48 \%$ for autologous transplantation, and 30\% for intensive chemotherapy. Interestingly these figures matched the results observed at that time from EBMT retrospective registry studies. However, the OS after CR was similar in the three groups, since more patients who relapsed after a second course of intensive chemotherapy had a response to subsequent ABMT. They concluded that autologous as well as allogeneic BMT resulted in better LFS than intensive consolidation chemotherapy.

These results were confirmed in 1998 by the UK MRC AML10 [59] study which randomized 381 patients to either intensive chemotherapy or ASCT. Of the 190 patients allocated to autologous BMT, 126 received it. On intention-to-treat analysis the number of relapses was substantially lower in the autologous BM group than in the group assigned to no further treatment (37\% versus $58 \%$, $p=0.0007)$, resulting in superior LFS at 7 years ( $53 \%$ versus $40 \%$; $p=0.04$ ). These benefits were observed in all risk groups and age groups. There were more deaths in remission in the autologous BM group than in the no further treatment group (12\% versus $4 \%$, $p=0008$ ). There was a trend for an OS advantage in the autologous BM transplant group at 7 years ( $57 \%$ versus $45 \%, p=0.2$ ).

In 1998, the French GOELAM group [60] randomized 367 patients who reached CR1 from an initial population of 517 patients up to 40 years of age, to receive either an allogeneic transplant with an HLA-identical sibling (if available) or after a first course of consolidation with high-dose cytarabine and anthracycline, to randomly receive a second course of consolidation with amsacrine and etoposide or a combination of busulfan and cyclosphosphamide, followed by an unpurged autologous BMT. There was no difference in outcome in the three groups. The absence of superiority of alloSCT which was unexpected, was difficult to explain.

Similarly, in 1998, the ECOG/SWOG/CALGB US intergroup [61] reported the results of a comparison of ABMT (purged with 4HC) versus allo-SCT versus high dose ARA-C. In an intention-totreat analysis, they found no significant differences in LFS among patients receiving high-dose chemotherapy, those undergoing $\mathrm{ABMT}$, and those undergoing allogeneic BMT. These data were also a subject of high controversy. Indeed, when they were reanalyzed using cytogenetics [62], the conclusion appeared somewhat different: it was found that patients with favorable cytogenetics did significantly better following ABMT and allogeneic BMT than chemotherapy alone, whereas patients with unfavorable cytogenetics did better with allogeneic BMT. Patients in the intermediate-risk cytogenetics group did equally well in the three arms.

Several other randomized studies have been reported. In the last meta-analysis [63] published in 2004, 1044 patients from six eligible studies were randomly assigned to receive ABMT or nonmyeloablative chemotherapy (five studies) or ABMT or no further treatment (one study). Compared with patients who received chemotherapy or no further treatment, patients who received ABMT had a better LFS $(p=0.006)$ but a similar OS. The authors concluded that the results did not support the routine use of autologous transplantation in adult AML in CR1. This can be challenged however, by the fact that NRM at that time was higher than at present, and also by the fact that reducing the relapse rate has often preceded any demonstration of a benefit in survival.

\section{AUTOLOGOUS STEM CELL TRANSPLANTATION FOR ACUTE MYELOID LEUKEMIA NOWADAYS}

\subsection{Recent Developments}

The considerable progress in allo-SCT which now makes it possible to transplant almost any AML patient, has resulted in a sharp decrease in the numbers of ASCT done each year for AML. Nonetheless, some advances in the field of ASCT have occurred regarding the optimization of the pre-transplant regimen and better selection of patients and disease status at transplant, to obtain a better outcome. In addition, the development of various maintenance therapies to reduce the risk of relapse post ASCT, including targeted drug therapies and immune therapies such as chimeric antigen receptor (CAR)-T cells have brought hope. Today, one option is to offer ASCT as an alternative to allo-SCT to goodand intermediate-risk patients in CR1 with no detectable MRD and thereby obtain similar LFS and OS with no risk of graft-versus-host disease (GVHD), mostly severe chronic GVHD and a better quality of life (QoL).

\subsection{A More Effective Myeloablative Pre-transplant Regimen}

The combination of cyclophosphamide (CY) $(60 \mathrm{mg} / \mathrm{kg} / \mathrm{day})+$ fractionated TBI (200 cGY morning and afternoon for 3 days) separated by a 2-day interval (either CY-FTBI or FTBI-CY) [64] or the combination BUCY $[31,65,66]$ (Busulfan $4 \mathrm{mg} / \mathrm{kg} / \mathrm{day}$ for 4 days followed by CY $60 \mathrm{mg} / \mathrm{kg} /$ day for 2 days) have been the historical myeloablative regimen pre-autograft. A specific reduced toxicity regimen, the busulfan, amsacrine, etoposide, cytosine-arabinoside 
(BAVC) was developed in Rome [57] and was well tolerated in older patients.

Other regimens including etoposide were tested with promising results: the Stanford team for example, combined high-dose etoposide with busulfan (BU-VP16) [67] and the Japanese [68] and Spanish Pethema group used a combination of busulfan, etoposide and cytosine-arabinoside.

Two recent improvements are of importance. Firstly, the shift from oral busulfan to intravenous (IV) administration. A recent retrospective analysis from the EBMT [69] has suggested a better LFS in AML patients in CR1 which is even more impressive in CR2: we analyzed data from 952 patients with AML who received intravenous busulfan for ASCT. Two-year OS, LFS, and RI were $67 \pm 2 \%$, $53 \pm 2 \%$, and $40 \pm 2 \%$, respectively. The NRM rate at 2 years was $7 \pm 1 \%$. Overall LFS and RI at 2 years did not differ significantly between the 815 patients transplanted in CR1 ( $52 \pm 2 \%$ and $40 \pm 2 \%$, respectively) and the 137 patients transplanted in CR2 (58 $\pm 5 \%$ and $35 \pm 5 \%$, respectively).

Secondly, the finding that the combination of IV busulfan and high-dose melphalan (BUMEL) was associated with the best OS (75 $\pm 4 \%)$, a finding that was in accordance with previous Italian studies from the Gruppo Italiano Malattie Ematologiche Maligne dell'Adulto (GIMEMA) group [70] which had already drawn attention to BUMEL.

The EBMT therefore reevaluated the various conditioning regimens [71,72] and confirmed the superiority of BUMEL over BUCY in a first limited series of 853 patients autografted in CR1. In a subsequent analysis, to identify the subpopulations that might best benefit from BUMEL, all adult patients with primary AML and with available cytogenetics, autografted from January 2000 to December 2016 in CR1 (1137 patients who received BUCY and 512 BUMEL) were evaluated in depth. In the poor-risk group defined as poor cytogenetics and/or presence of the FLT3-ITD mutation, BUMEL was associated with a lower RI at 5 years ( $53 \%$ versus $69 \%$; $p=0.002)$, a better LFS ( $42 \%$ versus $25 \%$; $p=0.002$ ) and a better OS ( $54 \%$ versus $36 \% ; p=0.02$ ). In the non-poor-risk group, there was no significant difference. The conclusion was that BUMEL is a more potent antileukemic combination and is the preferable conditioning regimen for the poor-risk leukemic patient, while in AML patients without poor-risk cytogenetics or FLT3 mutation, BUCY may remain a valid option.

Therefore, today the combination of IV busulfan and melphalan is our recommended pre-autografting regimen for adult AML in CR (Figure 4).

\subsection{A Better Selection of Patients}

Allogeneic stem cell transplantation has at first sight several advantages over ASCT for the curative treatment of adult AML: The first is the existence of the GVL effect; a second is the use in many instances (although not always) of reduced intensity conditioning; a third advantage is the recent possibility of using haploidentical donors as an alternative stem cell source which, combined with the other available sources, now makes it possible to offer an allo-transplant to almost any patient with AML who needs one.

\section{New vision for ASCT randomized studies}

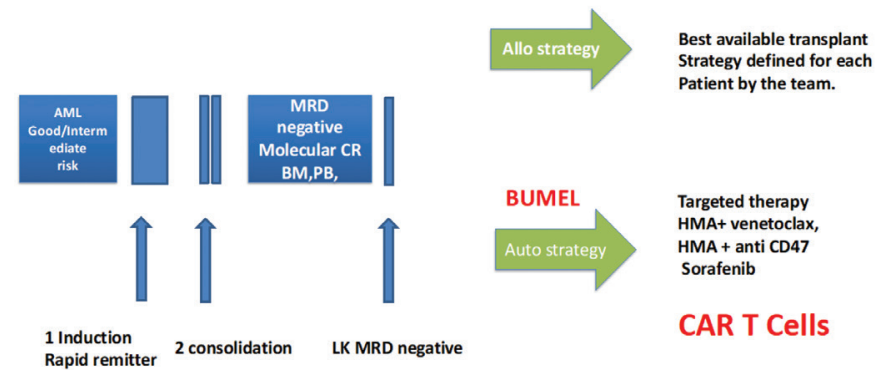

Figure 4 One possible scheme of a modern randomized study reassessing ASCT for the consolidation of patients with AML in MRD negative CR.

In contrast, depending upon the patient population and the status of the disease, allo-transplantation has a high NRM rate in the range of $15-25 \%$ and an incidence of severe chronic GVHD of approximately $10 \%$. For this reason, the outcome is nowadays expressed not only in terms of LFS and OS but also as the composite endpoint of GVHD-free, and relapse-free survival [73].

Autologous stem cell transplantation has some drawbacks, primarily the necessity to use a myeloablative regimen pre-transplant and a higher RI post-transplant. In contrast, it benefits from a much lower NRM and in the absence of GVHD a better QoL posttransplant [74-76]. Early attempts at generating GVHD/GVL post ASCT with interleukin-2 [77] or Cyclosporin A although promising, have failed [78] but they may have paved the way for the introduction of immune therapies (see below).

In view of these opposite advantages and inconvenience, the question that has been raised in the past decade is whether one can define a population of patients that may be cured of AML using ASCT, with a similar rate to allo-transplant, taking advantage of a lower NRM and resulting in a better QoL. Indeed, several retrospective studies have pointed out that adult AML patients in CR with no detectable residual tumor (MRD negative) using either flow cytometry and/or molecular biology may indeed achieve results similar to allo-transplantation. The present development of targeted therapies including immune therapies that might be given post ASCT further supports this approach.

Analyses from many registries have shown that ASCT benefits essentially AML patients classified as good- and intermediate-risk by cytogenetics, and not poor-risk patients in whom an allotransplant is the only potential curative approach: The Italian Group for Blood and Marrow Transplantation reported on a total of 809 patients autografted in CR1 [79] with 2-year LFS rates of $64 \pm 8 \%, 48 \pm 4 \%$ and $46 \pm 7 \%$ in good-, intermediate-, and poor-risk patients, respectively $(p<0.0001)$, while the 2 -year OS rates were $79 \pm 7 \%, 63 \pm 4 \%$ and $59 \pm 8 \%$, respectively. A multicenter retrospective study in Seoul (Korea) [80] revealed that younger patients aged $<40$ years old), with good- to intermediaterisk molecular cytogenetics, and who received limited doses of CD34(+) stem cells might be good candidates for ASCT with a 3-year LFS and RI of $83 \%$ and $17 \%$, respectively. Mizutani et al. [81] using the Japanese registry retrospectively compared the outcomes of patients who underwent autologous PBSC 
transplantation in CR1 (ASCT, $n=375$ ) with those who underwent allogeneic BMT $(n=521)$ and allo-PBSC $(n=380)$ from a matched sibling donor. The LFS of ASCT was not significantly different from that of allo-BMT (HR: $1.23 ; p=0.16$ ) and allo-PBSC (HR, $1.13 ; p=0.40)$. They concluded that auto-PBSC transplantation remains a promising alternative treatment for patients with AML in CR1 in the absence of an available matched sibling donor. They also reached the same conclusion when comparing ASCT to allo-transplants with matched unrelated donors [82] in patients who rapidly reached CR1 (so called rapid remitters).

For good-risk patients, the clinical value of allo-transplantation and ASCT has long remained unsettled. Nonetheless, among 2983 patients analyzed from seven published randomized protocols, Schlenk et al. [83] retrospectively identified 124 patients who had AML with double mutant CEBPA and achieved CR1. Relapsefree survival was significantly superior in patients receiving an allo-transplant or an ASCT in CR1 as compared with chemotherapy, whereas OS was not different. Interestingly these data from randomized studies matched the results of an earlier retrospective study from the EBMT [84] which showed similar outcomes post allo or auto in good-risk patients carrying inversion 16 or $t(8 ; 21)$ transplanted in CR1. Since the EBMT registry has no data on patients treated with chemotherapy only, no such comparison was feasible.

The question of the best consolidation regimen for patients after reaching CR1 has been studied by numerous teams in intermediate-risk patients. The Hovon group [85] using the European Leukemia Net (ELN) 2010 prognostic classification, has reported similar OS in this patient category, following a reduced intensity conditioning allo-transplant or an ASCT.

Several teams have reported superior results in patients consolidated while in CR and no detectable MRD. As an example, Messina et al. [86] evaluated WT1 transcript levels in autologous PBSCs from LK used for ASCT in 30 consecutive AML patients in CR and established a correlation with clinical outcome. Realtime quantitative PCR of WT1 was performed in samples of each LK. They defined a cut-off level of 80 WT1-LK copies/ABL $10^{4}$ copies to discriminate between positive and negative PBSC grafts. This cut-off level was strongly associated with disease recurrence, LFS and OS. Using the EBMT registry, we compared the outcome of 373 patients autografted and 335 patients allografted with a $10 / 10$ compatible unrelated donor in first molecular remission [87]. Patients were stratified using the ELN 2010 classification. We found that good-risk patients benefitted more from autologous transplantation; intermediate-II-risk patients had the same outcome and intermediate-I-risk patients (FLT3-ITD+) benefitted more from unrelated donor transplants. Indeed, the proof of concept sustaining the validity of ASCT for MRD negative patients in $\mathrm{CR}$ has been clearly established in acute promyelocytic leukemia, where ASCT has been demonstrated to be the best therapeutic consolidation option in patients who relapsed after first-line therapy and reached a CR2 MRD negative status [88-91]. In the most recent EBMT retrospective study on a large series of adult patients with APL in CR2 receiving allo-transplants $(n=228)$ or ASCT $(n=341)$ from January 2004 to December 2018, the 2-year cumulative incidence of NRM was significantly higher for allotransplants $(17.3 \%)$ compared with ASCT $(2.7 \%)(p=0.001)$, while differences in RI were not significant (28\% versus $22.9 \%$; $p=0.28)$. LFS and OS favored ASCT with $74.5 \%$ and $82.4 \%$ compared with allo-transplant with 54.7\% $(p=0.001)$ and $64.3 \%$ respectively ( $p=0.001$ and 0.001$)$.

The question of whether intermediate-risk patients reaching CR1 with no detectable residual disease can be consolidated by ASCT and obtain similar outcomes to allo-transplant (with potentially a better QoL) has been addressed by the randomized GIMEMA AML1310 trial of risk-adapted, MRD-directed therapy for young adults with newly diagnosed AML [92]. In this trial of 500 patients, post-remission therapy of young patients was decided by combining the disease risk classification and the post-consolidation levels of MRD. After induction and consolidation, favorable-risk patients (FR) were to receive ASCT and poor-risk patients (PR) allo-transplant. Intermediate-risk patients (IR) were to receive ASCT or allo-transplant depending on the post consolidation levels of MRD. Two-year OS and LFS of the whole series were $56 \%$ and $54 \%$, respectively. Two-year OS and LFS were $74 \%$ and $61 \%$ in the autografted FR risk category and $79 \%$ and $61 \%$ in the IR MRDnegative category. The investigators concluded that ASCT should have a role in FR and IR MRD-negative categories.

\subsection{Maintenance Therapy Post ASCT}

Relapse post-transplant remains a major issue in AML. Historically, following ASCT in CR1, the RI has been reported to be from 25\% with marrow purged in vitro with mafosfamide, and up to $45 \%$ more recently with PBSC at 2 years. Even more concerning is that late relapses occurs with an incidence of $7 \%$ at 5 years and $16 \%$ at 10 years [93]. This RI may be higher than the $15 \%$ usually observed post-allo-transplant.

Historically, stem cell transplantation (allo or auto) has always been considered as the last step in the treatment strategy since additional conventional chemotherapy post-transplant had not demonstrated efficacy. In the last decade however, the development of new therapeutic tools including targeted therapies has renewed interest in this approach. Some retrospective studies have shown a reduction in the RI post allo-transplant with maintenance therapies such as hypomethylating agents (azacytidine IV or p.o.; decitabine) and FLT3-ITD kinase inhibitors [94,95]. Two randomized studies have shown the benefit of sorafenib post-transplant: the German randomized trial (SORMAIN) [96] randomized 83 adult patients with FLT3-ITD-positive AML in complete hematologic remission after HCT to receive either sorafenib $(n=43)$ or placebo $(n=40)$. The 24 -month LFS probability was $53 \%$ with placebo versus $85 \%$ with sorafenib $(p=0.002)$. An open-label, multicenter phase 3 trial in China [97], randomized 202 patients with the FLT3-ITD mutation to receive or not, sorafenib maintenance $(400 \mathrm{mg}$ orally twice daily) at 30-60 days post-transplantation. The 1-year cumulative RI was lower (7\%) in the sorafenib group than in the control group $(24.5 \%)(p=0.0010)$. Similar approaches have not been tested so far after ASCT in good- and intermediaterisk patients but one can postulate a similar reduction in the RI. Furthermore, combinations of a hypomethylating agent (IV or oral) with venetoclax $[98,99]$, or with the anti-47 monoclonal antibody (magrolimab) [100] look even more effective and are currently being tested post-transplant. 
Table 1 Guidelines for selecting those patients who may get optimal benefit from autologous stem cell transplantation

\begin{tabular}{|c|c|c|c|c|c|c|c|c|c|}
\hline Patient & AML & $\begin{array}{l}\text { Cytogenetics } \\
\text { (MRC) }\end{array}$ & $\mathbf{E L N}^{\mathrm{a}}$ & Status & CR & Consolidation & MRD & $\begin{array}{l}\text { Pre-transplant } \\
\text { regimen }\end{array}$ & Maintenance \\
\hline \multirow[t]{2}{*}{$\begin{array}{l}\text { Up to } 75 \text { years } \\
\text { and fit }\end{array}$} & All but M3 & $\begin{array}{l}\text { Good or } \\
\text { Intermediate }\end{array}$ & $\begin{array}{l}\text { Favourable or } \\
\text { Intermediate } \\
\text { FLT3 unmutated }\end{array}$ & CR1 & Rapid remitter ${ }^{\mathrm{b}}$ & $\begin{array}{l}\text { At least } 2 \mathrm{HD} \\
\text { ARA-C courses } \\
\text { prior to LK }\end{array}$ & $\begin{array}{l}\text { Negative }^{c} \\
\text { All three } \\
\text { Marrow PB } \\
\text { LK }\end{array}$ & $\begin{array}{r}\text { BUMEL or } \\
\text { BUCY or } \\
\text { CY FTBI }\end{array}$ & $\begin{array}{l}\text { AZA + Venetoclax } \\
\text { AZA } \\
\text { CAR-T cells }\end{array}$ \\
\hline & M3 & & & CR2 & & & Negative & Same & \\
\hline
\end{tabular}

${ }^{a}$ ELN: European Leukemia Network prognostic classification 2010. ${ }^{b}$ Rapid remitter: reaching complete remission with only one induction chemotherapy course. ${ }^{c}$ No detectable residual disease by either flow cytometry and/or molecular biology. MRD, Minimal residual disease; MRC, UK Medical research council; HD ARA-C, High dose Cytosine-arabinoside; AZA, 5 Azacytidine.

\subsection{Current ASCT Activity for AML}

Data on about 50,000 autologous transplants for AML have been collected since 1980 by the two major registries, the EBMT in Europe and the Center for International Blood and Marrow Transplant Research in North America. But the number of ASCTs for AML in CR1 or CR2 has declined steadily since 2010 and 2015, the EBMT registry has collected annually not more than 300 ASCTs for myeloid malignancies (294 out of a total of 24,418 ASCT carried out in 2018).

Table 1 summarizes the best indications for ASCT in AML, in relation to the disease, the response to induction and consolidation therapy and the MRD evaluation. Some centers still propose ASCT to patients unwilling to receive an allo-transplant and/or to those ineligible according to the recommendations shown in Table 1.

The loss of interest as well as this reduced activity has unfortunately precluded the launch of randomized studies that would either compare ASCT to modern chemotherapy, targeted and/or immune therapies, or randomized studies that would evaluate the role of immune therapies post ASCT.

\section{AUTOLOGOUS STEM CELL TRANSPLANTATION AS A PLATFORM FOR IMMUNE THERAPIES}

The major impediment to a larger use of ASCT as consolidation for AML is in fact the absence of the GVL effect as seen with allo-transplant, despite early attempts at generating some immune anti-leukemic response post-transplant, either with interleukin-2, interferon, or histamine.

Immunotherapy post ASCT has been shown to be of major efficacy for lymphoid malignancies, in particular, with maintenance therapy with anti-CD20 monoclonal antibodies (rituximab or obinutuzumab) in patients with follicular and mantle cell lymphomas [101]. Likewise, the efficacy of lenalidomide post ASCT in multiple myeloma is demonstrated $[102,103]$ and the use of daratumumab maintenance post ASCT is being evaluated [104].

An even more important milestone has been the recent emergence of CAR-T cells, now widely used for the treatment of lymphomas (anti-CD20, CD22) and myelomas (anti-BCMA) and tested in combination with anti PD1 or PD1-L, before, after, or possibly before and after ASCT (https://clinical-hematology.org/special-webinars).

In AML, except for gemtuzumab-ozogamycin which targets CD33, no other effective immune therapy has demonstrated efficacy.
Present efforts focus on CAR-T cells with about 22 phase $1 / 2$ trials, some directed against CD33, CD123, FLT3, CD44v6 and the interleukin-1 receptor accessory protein (clinical.gouv NCT03267316) some CAR-T cells being in addition, on/off switchable [105-107]. If and when effective anti AML CAR-T cells become available, the question will arise as to how we will evaluate this new form of highly specific autoimmune lymphocyte infusion that mimics the allo donor lymphocyte infusion and that will bring to ASCT its missing immune anti-leukemic tool (mimicking the allo GVL effect).

\section{CONCLUSION}

In the past 45 years a considerable number of developments in the field of SCT have occurred and practices have changed. ASCT has become a routine part of the therapeutic platform for lymphoid malignancies and allo-SCT, the best curative treatment for most myeloid malignancies. Several historical transplant indications have almost disappeared, such as chronic myelocytic leukemia. Donors for allogeneic BMT have changed with a reduction in the use of cord blood. Unrelated donors have been replaced by haploidentical donors. ASCT which was very common for AML has remained a therapeutic option for a limited number of teams. It has however remained the best choice when compared with allo-SCT because of a lower NRM and a better QoL. Careful choice of patients based on prognostic score and undetectable MRD will continue to bring outcome benefit, but the future of ASCT will essentially rely on additional tools aimed at reducing the RI.

\section{CONFLICTS OF INTEREST}

The author declares no conflicts of interest.

\section{REFERENCES}

[1] Gorin NC. Collection, manipulation and freezing of haemopoietic stem cells. Clin Haematol 1986;15;19-48.

[2] Barnes DW, Loutit JF. The radiation recovery factor: preservation by the Polge-Smith-Parkes technique. J Natl Cancer Inst $1955 ; 15 ; 901-5$.

[3] Polge C, Smith AU, Parkes AS. Revival of spermatozoa after vitrification and dehydration at low temperatures. Nature 1949;164;666.

[4] Ashwood-Smith MJ. Preservation of mouse bone marrow at $-79^{\circ} \mathrm{C}$ with dimethyl sulphoxide. Nature 1961;190;1204-5. 
[5] Porter KA, Murray JE. Successful homotransplantation of rabbit bone marrow after preservation in glycerol at $-70^{\circ} \mathrm{C}$. Cancer Res $1958 ; 18 ; 117$.

[6] Buckner CD, Storb R, Dilligham LA, Thomas ED. Low temperature preservation of monkey marrow in dimethyl sulfoxide. Cryobiology 1970;7;136-40.

[7] Schaefer UW, Dicke KA, Van Bekkum DW. Recovery of hematopoiesis in lethally irradiated monkeys by frozen allogeneic bone marrow grafts. Rev Eur Etud Clin Biol 1972;17;483-8.

[8] Gorin NC, Bull MI, Herzig GP, Graw RG. Long term preservation of bone marrow for autologous bone marrow transplantation. Clin Res 1975;23;338a.

[9] Gorin NC, Elgjo R, Stout F, Knutsen T. Long-term preservation of canine bone marrow: in vitro studies. Blood Cells 1978;4;419-33.

[10] Gorin NC, Herzig G, Bull MI, Graw RG. Long-term preservation of bone marrow and stem cell pool in dogs. Blood 1978;51; 257-65.

[11] Appelbaum FR, Herzig GP, Graw RG, Bull MI, Bowles C, Gorin NC, et al. Study of cell dose and storage time on engraftment of cryopreserved autologous bone marrow in a canine model. Transplantation 1978;26;245-8.

[12] Cavins JA, Kasakura S, Thomas ED, Ferrebee JW. Recovery of lethally irradiated dogs following infusion of autologous marrow stored at low temperature in dimethyl-sulphoxide. Blood $1962 ; 20 ; 730-4$.

[13] Epstein RB, Storb R, Clift RA, Thomas ED. Autologous bone marrow grafts in dogs treated with lethal doses of cyclophosphamide. Cancer Res 1969;29;1072-5.

[14] Douay L, Gorin NC, David R, Stachowiak J, Salmon C, Najman A, et al. Study of granulocyte-macrophage progenitor (CFUc) preservation after slow freezing of bone marrow in the gas phase of liquid nitrogen. Exp Hematol 1982;10;360-6.

[15] Douay L, Gorin NC, Mary JY, Lemarie E, Lopez M, Najman A, et al. Recovery of CFU-GM from cryopreserved marrow and in vivo evaluation after autologous bone marrow transplantation are predictive of engraftment. Exp Hematol 1986;14;358-65.

[16] Douay L, Lopez M, Gorin NC. A technical bias: differences in cooling rates prevent ampoules from being a reliable index of stem cell cryopreservation in large volumes. Cryobiology 1986;23;296-301.

[17] Aird W, Labopin M, Gorin NC, Antin JH. Long-term cryopreservation of human stem cells. Bone Marrow Transplant 1992;9; 487-90.

[18] Burnett AK, Tansey P, Hills C, Alcorn MJ, Sheehan T, McDonald GA, et al. Haematological reconstitution following high dose and supralethal chemo-radiotherapy using stored, non-cryopreserved autologous bone marrow. Br J Haematol 1983;54;309-16.

[19] Bekadja MA, Brahimi M, Osmani S, Arabi A, Bouhass R, Yafour $\mathrm{N}$, et al. A simplified method for autologous stem cell transplantation in multiple myeloma. Hematol Oncol Stem Cell Ther 2012;5;49-53.

[20] Bittencourt MCB, Mariano L, Moreira F, Schmidt-Filho J, Mendrone-Jr A, Rocha V. Cryopreserved versus noncryopreserved peripheral blood stem cells for autologous transplantation after high-dose Melphalan in multiple myeloma: comparative analysis. Bone Marrow Transplant 2019;54;138-41.

[21] Ruiz-Argüelles GJ, Gómez-Rangel D, Ruiz-Delgado GJ, RuizArgüelles A, Pérez-Romano B, Rivadeneyra L. Results of an autologous noncryopreserved, unmanipulated peripheral blood hematopoietic stem cell transplant program: a single-institution, 10-year experience. Acta Haematol 2003;110;179-83.

[22] Sierra J, Conde E, Iriondo A, Brunet S, Marín J, Pérez de Oteiza J, et al. Frozen vs. nonfrozen bone marrow for autologous transplantation in lymphomas: a report from the Spanish GEL/TAMO Cooperative Group. Ann Hematol 1993;67;111-14.

[23] Bekadja MA, Boumendil A, Blaise D, Chevallier P, Peggs KS, Salles G, et al. Non-cryopreserved hematopoietic stem cells in autograft patients with lymphoma: a matched-pair analysis comparing a single center experience with the use of cryopreserved stem cells reported to the European Society for Blood and Marrow Transplantation registry. Cytotherapy $2021 ; 23 ; 483-7$.

[24] Ruiz-Argüelles GJ. Lessons learned starting a bone marrow transplantation programme in a resource-constrained setting. Lancet Haematol 2020;7;e509-e10.

[25] Gorin NC, Duhamel G. Conservation de cellules souches hematopoietiques par congelation lente et elimination de la chaleur de fusion. Acad Sci Paris 1978;286;547-50.

[26] Gorin NC, Najman A, David R, Stachowiak J, Hirsch Marie F, Muller JY, et al. [High dose combination chemotherapy with and without autologous bone marrow transplantation in patients with solid tumors and acute leukemias. Kinetics of recovery of peripheral bloods cells (author's transl)]. Nouv Presse Med 1978;7;4105-10 (in French).

[27] Gorin NC, Najman A, Duhamel G. Autologous bone-marrow transplantation in acute myelocytic leukaemia. Lancet 1977; 309; 1050 .

[28] Gorin NC, David R, Stachowiak J, Salmon C, Petit JC, Parlier $\mathrm{Y}$, et al. High dose chemotherapy and autologous bone marrow transplantation in acute leukemias, malignant lymphomas and solid tumors: a study of 23 patients. Eur J Cancer 1981;17; 557-68.

[29] Gorin NC, Douay L, David R, Stachowiak J, Parlier Y, Oppenheimer M, et al. Delayed kinetics of recovery of hematopoiesis following autologous bone marrow transplantation: the role of excessively rapid marrow freezing rates after the release of fusion heat. Eur J Cancer Clin Oncol 1983;19;485-91.

[30] Sharkis SJ, Santos GW, Colvin M. Elimination of acute myelogenous leukemic cells from marrow and tumor suspensions in the rat with 4-hydroperoxycyclophosphamide. Blood 1980;55; $521-3$.

[31] Yeager AM, Kaizer H, Santos GW, Saral R, Colvin OM, Stuart RK, et al. Autologous bone marrow transplantation in patients with acute nonlymphocytic leukemia, using ex vivo marrow treatment with 4-hydroperoxycyclophosphamide. N Engl J Med 1986;315;141-7.

[32] Hervé P, Cahn JY, Plouvier E, Flesch M, Tamayo E, Leconte des Floris R, et al. Autologous bone marrow transplantation for acute leukemia using transplant chemopurified with metabolite of oxazaphosphorines (ASTA Z 7557, INN mafosfamide). First clinical results. Invest New Drugs 1984;2;245-52.

[33] Lopez M, Duc Puy-Montbrun MC, Douay L, Laporte JP, Gorin NC. Standardization and characterization of the procedure for in vitro treatment of human bone marrow with cyclophosphamide derivatives. Clin Lab Haematol 1985;7;327-34.

[34] Gorin NC, Douay L, Laporte JP, Lopez M, Mary JY, Najman A, et al. Autologous bone marrow transplantation using marrow incubated with Asta Z 7557 in adult acute leukemia. Blood $1986 ; 67 ; 1367-76$. 
[35] Douay L, Gorin NC, Laporte JP, Lopez M, Najman A, Duhamel G. ASTA Z 7557 (INN mafosfamide) for the in vitro treatment of human leukemic bone marrows. Invest New Drugs 1984;2; 187-90.

[36] Douay L, Gorin NC, Gerota I, Najman A, Duhamel G. In vitro treatment of leukemic bone marrow for autologous transplantation. Exp Hematol 1982;10;113-22.

[37] Körbling M, Dörken B, Tischbirek K, Zipperle G, Ho AD, Fliedner TM, et al. Autologous transplantation of a bone marrow graft manipulated by chemoseparation to eliminate residual tumor cells. Blut 1983;46;89-93.

[38] van den Akker J, Gorin NC, Laporte JP, Douay L, Lopez M, Taillemite JL, et al. Chromosome abnormalities after autologous bone marrow transplantation with marrow treated by cyclophosphamide derivatives. Lancet 1985;325;1211-12.

[39] Perot C, van den Akker J, Laporte JP, Douay L, Lopez M, Stachowiak J, et al. Multiple chromosome abnormalities in patients with acute leukemia after autologous bone marrow transplantation using total body irradiation and marrow purged with mafosfamide. Leukemia 1993;7;509-15.

[40] Allieri MA, Lopez M, Douáy L, Mary JY, Nguyen L, Gorin NC. Clonogenic leukemic progenitor cells in acute myelocytic leukemia are highly sensitive to cryopreservation: possible purging effect for autologous bone marrow transplantation. Bone Marrow Transplant 1991;7;101-5.

[41] Gorin NC, Labopin M, Laporte JP, Douay L, Lopez M, Lesage S, et al. Importance of marrow dose on posttransplant outcome in acute leukemia: models derived from patients autografted with mafosfamide-purged marrow at a single institution. Exp Hematol 1999;27;1822-30.

[42] Gorin NC, Aegerter P, Auvert B, Meloni G, Goldstone AH, Burnett A, et al. Autologous bone marrow transplantation for acute myelocytic leukemia in first remission: a European survey of the role of marrow purging. Blood 1990;75;1606-14.

[43] Gorin NC, Labopin M, Meloni G, Korbling M, Carella A, Herve P, et al. Autologous bone marrow transplantation for acute myeloblastic leukemia in Europe: further evidence of the role of marrow purging by mafosfamide. European Co-operative Group for Bone Marrow Transplantation (EBMT). Leukemia 1991;5;896-904.

[44] Miller CB, Rowlings PA, Zhang MJ, Jones RJ, Piantadosi S, Keating A, et al. The effect of graft purging with 4-hydroperoxycyclophosphamide in autologous bone marrow transplantation for acute myelogenous leukemia. Exp Hematol 2001;29;1336-46.

[45] Brenner MK, Krance R, Heslop HE, Santana V, Ihle J, Ribeiro R, et al. Assessment of the efficacy of purging by using gene marked autologous marrow transplantation for children with AML in first complete remission. Human Gene Ther 1994;5;481-99.

[46] Brenner MK, Rill DR, Krance RA, Ihle JN, Moen RC, Mirro J, et al. Gene-marking to trace origin of relapse after autologous bone-marrow transplantation. Lancet 1993;341;85-6.

[47] Mehta J, Powles R, Singhal S, Treleaven J. Peripheral blood stem cell transplantation may result in increased relapse of acute myeloid leukaemia due to reinfusion of a higher number of malignant cells. Bone Marrow Transplant 1995;15;652-3.

[48] Laporte JP, Gorin NC, Feuchtenbaum J, Lopez M, Douay L, LyonCaen D, et al. Relapse after autografting with peripheral blood stem cells. Lancet 1987;330;1393.

[49] Jourdan E, Rigal-Huguet F, Marit G, Vey N, Dastugue N, Fegueux $\mathrm{N}$, et al. One versus two high-dose cytarabine-based consolidation before autologous stem cell transplantation for young acute myeloblastic leukaemia patients in first complete remission. Br J Haematol 2005;129;403-10.

[50] Reiffers J, Labopin M, Sanz M, Korbling M, Blaise D, De La Rubia J, et al. Autologous blood cell vs marrow transplantation for acute myeloid leukemia in complete remission: an EBMT retrospective analysis. Bone Marrow Transplant 2000;25;1115-19.

[51] Gorin NC, Labopin M, Blaise D, Reiffers J, Meloni G, Michallet $\mathrm{M}$, et al. Higher incidence of relapse with peripheral blood rather than marrow as a source of stem cells in adults with acute myelocytic leukemia autografted during the first remission. J Clin Oncol 2009;27;3987-93.

[52] Feller N, Schuurhuis GJ, van der Pol MA, Westra G, Weijers GWD, van Stijn A, et al. High percentage of CD34-positive cells in autologous AML peripheral blood stem cell products reflects inadequate in vivo purging and low chemotherapeutic toxicity in a subgroup of patients with poor clinical outcome. Leukemia $2003 ; 17 ; 68-75$.

[53] Shouval R, Labopin M, Gorin NC, Bomze D, Houhou M, Blaise $\mathrm{D}$, et al. Individualized prediction of leukemia-free survival after autologous stem cell transplantation in acute myeloid leukemia. Cancer 2019;125;3566-73.

[54] Gorin NC. Autologous stem cell transplantation in acute myelocytic leukemia. Blood 1998;92;1073-90.

[55] Linker CA, Ries CA, Damon LE, Rugo HS, Wolf JL. Autologous bone marrow transplantation for acute myeloid leukemia using busulfan plus etoposide as a preparative regimen. Blood 1993;81;311-18.

[56] Linker CA, Ries CA, Damon LE, Rugo HS, Wolf JL. Autologous bone marrow transplantation for acute myeloid leukemia using 4-hydroperoxycyclophosphamide-purged bone marrow and the busulfan/etoposide preparative regimen: a follow-up report. Bone Marrow Transplant 1998;22;865-72.

[57] Meloni G, Vignetti M, Avvisati G, Capria S, Micozzi A, Giona F, et al. BAVC regimen and autograft for acute myelogenous leukemia in second complete remission. Bone Marrow Transplant $1996 ; 18 ; 693-8$.

[58] Zittoun RA, Mandelli F, Willemze R, de Witte T, Labar B, Resegotti $\mathrm{L}$, et al. Autologous or allogeneic bone marrow transplantation compared with intensive chemotherapy in acute myelogenous leukemia. European Organization for Research and Treatment of Cancer (EORTC) and the Gruppo Italiano Malattie Ematologiche Maligne dell'Adulto (GIMEMA) Leukemia Cooperative Groups. N Engl J Med 1995;332;217-23.

[59] Burnett AK, Goldstone AH, Stevens RM, Hann IM, Rees JK, Gray RG, et al. Randomised comparison of addition of autologous bone-marrow transplantation to intensive chemotherapy for acute myeloid leukaemia in first remission: results of MRC AML 10 trial. UK Medical Research Council Adult and Children's Leukaemia Working Parties. Lancet 1998;351;700-8.

[60] Harousseau JL, Cahn JY, Pignon B, Witz F, Milpied N, Delain $\mathrm{M}$, et al. Comparison of autologous bone marrow transplantation and intensive chemotherapy as postremission therapy in adult acute myeloid leukemia. The Groupe Ouest Est Leucémies Aiguës Myéloblastiques (GOELAM). Blood 1997;90; 2978-86.

[61] Cassileth PA, Harrington DP, Appelbaum FR, Lazarus HM, Rowe JM, Paietta E, et al. Chemotherapy compared with autologous or allogeneic bone marrow transplantation in the management of acute myeloid leukemia in first remission. N Engl J Med 1998;339;1649-56. 
[62] Slovak ML, Kopecky KJ, Cassileth PA, Harrington DH, Theil KS, Mohamed A, et al. Karyotypic analysis predicts outcome of preremission and postremission therapy in adult acute myeloid leukemia: a Southwest Oncology Group/Eastern Cooperative Oncology Group Study. Blood 2000;96;4075-83.

[63] Nathan PC, Sung L, Crump M, Beyene J. Consolidation therapy with autologous bone marrow transplantation in adults with acute myeloid leukemia: a meta-analysis. J Natl Cancer Inst 2004;96;38-45.

[64] Thomas ED, Buckner CD, Banaji M, Clift RA, Fefer A, Flournoy $\mathrm{N}$, et al. One hundred patients with acute leukemia treated by chemotherapy, total body irradiation, and allogeneic marrow transplantation. Blood 1977;49;511-33.

[65] Santos GW, Tutschka PJ, Brookmeyer R, Saral R, Beschorner WE, Bias WB, et al. Marrow transplantation for acute nonlymphocytic leukemia after treatment with busulfan and cyclophosphamide. N Engl J Med 1983;309;1347-53.

[66] Tutschka PJ, Copelan EA, Klein JP. Bone marrow transplantation for leukemia following a new busulfan and cyclophosphamide regimen. Blood 1987;70;1382-8.

[67] Chao NJ, Stein AS, Long GD, Negrin RS, Amylon MD, Wong RM, et al. Busulfan/etoposide-initial experience with a new preparatory regimen for autologous bone marrow transplantation in patients with acute nonlymphoblastic leukemia. Blood $1993 ; 81 ; 319-23$.

[68] Gondo H, Harada M, Miyamoto T, Takenaka K, Tanimoto K, Mizuno S, et al. Autologous peripheral blood stem cell transplantation for acute myelogenous leukemia. Bone Marrow Transplantation 1997;20;821-6.

[69] Nagler A, Labopin M, Gorin NC, Ferrara F, Sanz MA, Wu D, et al. Intravenous busulfan for autologous stem cell transplantation in adult patients with acute myeloid leukemia: a survey of 952 patients on behalf of the Acute Leukemia Working Party of the European Group for Blood and Marrow Transplantation. Haematologica 2014;99;1380-6.

[70] Lemoli RM, D’Addio A, Marotta G, Pezzullo L, Zuffa E, Montanari $\mathrm{M}$, et al. BU/melphalan and auto-SCT in AML patients in first CR: a 'Gruppo Italiano Trapianto di Midollo Osseo (GITMO)' retrospective study. Bone Marrow Transplant 2010;45;640-6.

[71] Gorin NC, Labopin M, Blaise D, Dumas PY, Pabst T, Trisolini $\mathrm{SM}$, et al. Optimizing the pretransplant regimen for autologous stem cell transplantation in acute myelogenous leukemia: better outcomes with busulfan and melphalan compared with busulfan and cyclophosphamide in high risk patients autografted in first complete remission: a study from the acute leukemia working party of the EBMT. Am J Hematol 2018;93;859-66.

[72] Gorin NC, Labopin M, Czerw T, Pabst T, Blaise D, Dumas PY, et al. Autologous stem cell transplantation for adult acute myelocytic leukemia in first remission-Better outcomes after busulfan and melphalan compared with busulfan and cyclophosphamide: a retrospective study from the Acute Leukemia Working Party of the European Society for Blood and Marrow Transplantation (EBMT). Cancer 2017;123;824-31.

[73] Ruggeri A, Labopin M, Ciceri F, Mohty M, Nagler A. Definition of GvHD-free, relapse-free survival for registry-based studies: an ALWP-EBMT analysis on patients with AML in remission. Bone Marrow Transplant 2016;51;610-11.

[74] Watson M, Buck G, Wheatley K, Homewood JR, Goldstone AH, Rees JKH, et al. Adverse impact of bone marrow transplantation on quality of life in acute myeloid leukaemia patients; analysis of the UK Medical Research Council AML 10 Trial. Eur J Cancer 2004; $40 ; 971-8$.

[75] Zittoun R, Suciu S, Watson M, Solbu G, Muus P, Mandelli F, et al. Quality of life in patients with acute myelogenous leukemia in prolonged first complete remission after bone marrow transplantation (allogeneic or autologous) or chemotherapy: a cross-sectional study of the EORTC-GIMEMA AML 8A trial. Bone Marrow Transplant 1997;20;307-15.

[76] Sun CL, Francisco L, Kawashima T, Leisenring W, Robison LL, Scott Baker K, et al. Prevalence and predictors of chronic health conditions after hematopoietic cell transplantation: a report from the Bone Marrow Transplant Survivor Study. Blood 2010;116;3129-39.

[77] Hamon MD, Prentice HG, Gottlieb DJ, Macdonald ID, Cunningham JM, Smith OP, et al. Immunotherapy with interleukin 2 after ABMT in AML. Bone Marrow Transplant 1993;11;399-401.

[78] Santos GW. Autologous graft-versus-host disease. Leukemia $1992 ; 6 ; 110-11$.

[79] Saraceni F, Bruno B, Lemoli RM, Meloni G, Arcese W, Falda M, et al. Autologous stem cell transplantation is still a valid option in good- and intermediate-risk AML: a GITMO survey on 809 patients autografted in first complete remission. Bone Marrow Transplant 2017;52;163-6.

[80] Yoon JH, Kim HJ, Park SS, Jeon YW, Lee SE, Cho BS et al. Clinical outcome of autologous hematopoietic cell transplantation in adult patients with acute myeloid leukemia: who may benefit from autologous hematopoietic cell transplantation? Biol Blood Marrow Transplant 2017;23;588-97.

[81] Mizutani M, Hara M, Fujita H, Aoki J, Kanamori H, Ohashi K, et al. Comparable outcomes between autologous and allogeneic transplant for adult acute myeloid leukemia in first CR. Bone Marrow Transplant 2016;51;645-53.

[82] Mizutani M, Takami A, Hara M, Mizuno S, Yanada M, Chou T, et al. Comparison of autologous and unrelated transplants for cytogenetically normal acute myelogenous leukemia. Biol Blood Marrow Transplant 2017;23;1447-54.

[83] Schlenk RF, Taskesen E, van Norden Y, Krauter J, Ganser A, Bullinger L, et al. The value of allogeneic and autologous hematopoietic stem cell transplantation in prognostically favorable acute myeloid leukemia with double mutant CEBPA. Blood 2013;122;1576-82.

[84] Gorin NC, Labopin M, Frassoni F, Milpied N, Attal M, Blaise D, et al. Identical outcome after autologous or allogeneic genoidentical hematopoietic stem-cell transplantation in first remission of acute myelocytic leukemia carrying inversion 16 or $\mathrm{t}(8 ; 21)$ : a retrospective study from the European Cooperative Group for Blood and Marrow Transplantation. J Clin Oncol 2008;26; 3183-8.

[85] Cornelissen JJ, Blaise D. Hematopoietic stem cell transplantation for patients with AML in first complete remission. Blood $2016 ; 127 ; 62-70$.

[86] Messina C, Candoni A, Carrabba MG, Tresoldi C, Sala E, Tassara $\mathrm{M}$, et al. Wilms' tumor gene 1 transcript levels in leukapheresis of peripheral blood hematopoietic cells predict relapse risk in patients autografted for acute myeloid leukemia. Biol Blood Marrow Transplant 2014;20;1586-91.

[87] Gorin NC, Labopin M, Pabst T, Remenyi P, Wu D, Huynh A, et al. Unrelated matched versus autologous transplantation in adult patients with good and intermediate risk acute 
myelogenous leukemia in first molecular remission. Am J Hematol 2017;92;1318-23.

[88] Ganzel C, Mathews V, Alimoghaddam K, Ghavamzadeh A, Kuk D, Devlin S, et al. Autologous transplant remains the preferred therapy for relapsed APL in CR2. Bone Marrow Transplant 2016;51;1180-3.

[89] Holter Chakrabarty JL, Rubinger M, Le-Rademacher J, Wang HL, Grigg A, Selby GB, et al. Autologous is superior to allogeneic hematopoietic cell transplantation for acute promyelocytic leukemia in second complete remission. Biol Blood Marrow Transplant 2014;20;1021-5.

[90] Meloni G, Diverio D, Vignetti M, Avvisati G, Capria S, Petti $\mathrm{MC}$, et al. Autologous bone marrow transplantation for acute promyelocytic leukemia in second remission: prognostic relevance of pretransplant minimal residual disease assessment by reverse-transcription polymerase chain reaction of the PML/ RAR alpha fusion gene. Blood 1997;90;1321-5.

[91] Sanz J, Labopin M, Sanz MA, Aljurf M, Sousa AB, Craddock C, et al. Hematopoietic stem cell transplantation for adults with relapsed acute promyelocytic leukemia in second complete remission. Bone Marrow Transplant 2021;56;1272-80.

[92] Venditti A, Piciocchi A, Candoni A, Melillo L, Calafiore V, Cairoli R, et al. GIMEMA AML1310 trial of risk-adapted, MRD-directed therapy for young adults with newly diagnosed acute myeloid leukemia. Blood 2019;134;935-45.

[93] Czerw T, Labopin M, Gorin N, Giebel S, Blaise D, Meloni G, et al. Long term follow up of autologous hematopoietic stem cell transplantation for acute myeloid leukemia: a survey of 3567 patients in CR at two years post transplantation, from the acute leukemia working party of the EBMT. Cancer 2016;122;1880-7.

[94] Battipaglia G, Massoud R, Ahmed SO, Legrand O, El Cheikh J, Youniss R, et al. Efficacy and feasibility of sorafenib as a maintenance agent after allogeneic hematopoietic stem cell transplantation for Fms-like tyrosine kinase 3 mutated acute myeloid leukemia: an update. Clin Lymphoma Myeloma Leuk 2019;19;506-8.

[95] Battipaglia G, Ruggeri A, Massoud R, El Cheikh J, Jestin M, Antar A, et al. Efficacy and feasibility of sorafenib as a maintenance agent after allogeneic hematopoietic stem cell transplantation for Fms-like tyrosine kinase 3-mutated acute myeloid leukemia. Cancer 2017;123;2867-74.

[96] Burchert A, Bug G, Fritz LV, Finke J, Stelljes M, Röllig C, et al. Sorafenib maintenance after allogeneic hematopoietic stem cell transplantation for acute myeloid leukemia with FLT3-internal tandem duplication mutation (SORMAIN). J Clin Oncol 2020; 38;2993-3002.
[97] Xuan L, Wang Y, Huang F, Fan Z, Xu Y, Sun J, et al. Sorafenib maintenance in patients with FLT3-ITD acute myeloid leukaemia undergoing allogeneic haematopoietic stem-cell transplantation: an open-label, multicentre, randomised phase 3 trial. Lancet Oncol 2020;21;1201-12.

[98] DiNardo CD, Jonas BA, Pullarkat V, Thirman MJ, Garcia JS, Wei $\mathrm{AH}$, et al. Azacitidine and venetoclax in previously untreated acute myeloid leukemia. N Engl J Med 2020;383; 617-29.

[99] Ball BJ, Famulare CA, Stein EM, Tallman MS, Derkach A, Roshal M, et al. Venetoclax and hypomethylating agents (HMAs) induce high response rates in MDS, including patients after HMA therapy failure. Blood Adv 2020;4;2866-70.

[100] Chao MP, Takimoto CH, Feng DD, McKenna K, Gip G, Liu J, et al. Therapeutic targeting of the macrophage immune checkpoint CD47 in myeloid malignancies. Front Oncol 2020;9;1380.

[101] Le Gouill S, Thieblemont C, Oberic L, Moreau A, Bouabdallah K, Dartigeas C, et al. Rituximab after autologous stem-cell transplantation in mantle-cell lymphoma. N Engl J Med 2017;377; 1250-60.

[102] McCarthy PL, Holstein SA, Petrucci MT, Richardson PG, Hulin C, Tosi P, et al. Lenalidomide maintenance after autologous stem-cell transplantation in newly diagnosed multiple myeloma: a meta-analysis. J Clin Oncol 2017;35;3279-89.

[103] Attal M, Lauwers-Cances V, Marit G, Caillot D, Moreau P, Facon T, et al. Lenalidomide maintenance after stem-cell transplantation for multiple myeloma. N Engl J Med 2012;366; 1782-91.

[104] Dimopoulos MA, Jakubowiak AJ, McCarthy PL, Orlowski RZ, Attal M, Bladé J, et al. Developments in continuous therapy and maintenance treatment approaches for patients with newly diagnosed multiple myeloma. Blood Cancer J 2020; $10 ; 17$.

[105] Prommersberger S, Jetani H, Danhof S, Monjezi R, Nerreter T, Beckmann J, et al. Novel targets and technologies for CAR-T cells in multiple myeloma and acute myeloid leukemia. Curr Res Transl Med 2018;66;37-8.

[106] Hofmann S, Schubert ML, Wang L, He B, Neuber B, Dreger P, et al. Chimeric antigen receptor (CAR) $\mathrm{T}$ cell therapy in acute myeloid leukemia (AML). J Clin Med 2019;8;200.

[107] Jetani H, Garcia-Cadenas I, Nerreter T, Thomas S, Rydzek J, Meijide JB, et al. CAR T-cells targeting FLT3 have potent activity against FLT3-ITD $^{+}$AML and act synergistically with the FLT3-inhibitor crenolanib. Leukemia 2018;32; 1168-79. 